\title{
琼雷地区玻璃陨石的化学组成和 热释光特性初步研究
}

\author{
郑洪汉黄宝林 高三玫 \\ （中国科学院地球化学研究所广州分部,广州 510640; \\ 中国科学院西安黄土与第四纪地质开故研究实验室,西安 710061)
}

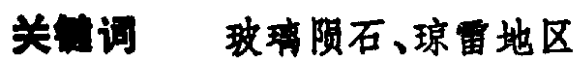

玻璃陨石(雷公墨)在世界各大洲的许多地点都有发现, 并主要集中于亚澳区、象牙海岸 区、莫尔达维区和北美区. 四个地区玻璃陨石的同位素年龄分别为距今 70 万年、110 万年、 1450 万年和 3450 万年.我国的玻璃陨石主要集中在雷洲半岛和海南离. 近年在茂名、电白、阳 江等地也有发现, 其分布区已超出了琼雷地区范围. 分布的经纬位置大约在 $18^{\circ} 20^{\prime}-21^{\circ} 50^{\prime} \mathrm{N}$. 和 $108^{\circ} 30^{\circ}-111^{\circ} 30^{\prime} \mathrm{E}$ 之间. 近十多年来, 我国科学工作者对该区玻璃陨石已做了许多工作, 结论认为琼雷地区的玻璃陨石形成于距今约 0.7 百万年 ${ }^{[1,2]}$, 其化学组成和年代学数据表明, 它 应属亚澳散落区的一部分 ${ }^{[3-6]}$, 并且是区域地层划分和对比的一个重要标志 ${ }^{[1}$. 从有关文献看, 䧑石出土的地层层位并不完全一致,有的含于北海组下部,而大多数则产自北海组和湛江组的， 地层界面上. 我们考察所见,许多地点的玻璃陨石都残留于地表, 其地层层位并不十分清楚. 目前人们对北海组和湛江组的认识不完全统一, 各地样品通过裂变径迹法测得的陨落年龄也 不尽相同. 这样则有必要对它作进一步研究。笔者选取了产自吴川罩巴(样号 02) 和海南琼 山县大致坡(样号 06 , 称南河陨石)两地的样品分内外层作了 X射线衍射、红外光谱、化学成分 和热释光特性分析, 目的是检查一下分属琼雷两地区的样品以及同一地区样品内外层在物质 组成和结构上是否存在差异.

表 1 所列系应用原子吸收光谱分析所获结果. 数据表明, 吴川和琼山样品, 以及两地样品 内外层的化学组成基本一致,并与澳洲玻璃陨石的化学组成一致. 两地样品的微细差别是: 吴 川样品的 $\mathrm{Al} 、 \mathrm{Fe} 、 \mathrm{Mg} 、 \mathrm{Ca}$ 含量均高于琼山所产陨石样品的含量.

元素含是的微细差异还可能表现在陨石体结构和元素在隄石体中分布的不同．为探讨不 同地点和同一地点隄石体结构和元素分有差异所表现的热释光特性, 对上述样品进行了热释 光特性分析,其自然积存热释光及 $\beta$ 辐射后的热释光曲线如图 1 所示,相应的参数值列于表 2 .

数据表明,两地样品内外层无多大差异, 自然积存热释光均在 340 和 $360^{\circ} \mathrm{C}$ 出现单盽, 高 温平稳,并有良好坪区; 但吴川样品的热释光峰不明显, 而且峰值温度偏高. 样品对 $\beta$ 辐射的 热释光响应不灵敏, 采用较大剂量辐射后, 除高温峰外尚出现 $158^{\circ} \mathrm{C}$ 蜂。在相同试验条件下, $N+\beta$ 的低温峰强度表现为, 吴川样品外层大于内层, 而琼山样品则内层大于外层。

红外光谱分析结果表明,两地内外层 4 个样品均在波数为 $1080 \mathrm{~cm}^{-1}$ 和 $460 \mathrm{~cm}^{-1}$ 处出现吸

本文1989 年6月20日收到. 
表 1 琼䨞玻璃隄石化学成分及其与渙洲玻璃隆石成分对比(\%)

\begin{tabular}{|c|c|c|c|c|c|}
\hline 素 & \multicolumn{2}{|c|}{ 吴么院石 } & \multicolumn{2}{|c|}{ 琮山陨石 } & \multirow{2}{*}{ 洪洲陨石 ${ }^{[1,2]}$} \\
\hline & 内层 $(02-1)$ & 外层 $(02-2)$ & 内层 $(0 G-1)$ & 外层(06-2) & \\
\hline $\mathbf{O}$ & 48.02 & 47.96 & 48.35 & 48.51 & 48.19 \\
\hline Si & 32.55 & 32.51 & 34.06 & 33.61 & 32.91 \\
\hline Al & 7.12 & 7.12 & 6.51 & 6.64 & 7.60 \\
\hline $\mathbf{M g}$ & 1.44 & 1.43 & 1.18 & 1.20 & 1.33 \\
\hline $\mathrm{Fe}^{+3}$ & 1.10 & 1.11 & 0.88 & 1.16 & 1386 \\
\hline $\mathrm{Fe}^{+2}$ & 2.71 & 2.65 & 2.55 & 2.36 & 3.80 \\
\hline $\mathbf{N a}$ & 0.98 & 0.98 & 0.98 & 1.04 & 1.16 \\
\hline$C_{a}$ & 1.92 & 1.91 & 1.38 & 1.52 & 2.10 \\
\hline $\mathbf{K}$ & 2.13 & 2.15 & 2.03 & 2.14 & \\
\hline $\mathbf{T i}$ & 0.48 & 0.48 & 0.44 & 0.45 & \\
\hline $\mathbf{M n}$ & 0.07 & 0.07 & 0.06 & 0.07 & \\
\hline $\mathbf{p}$ & 0.03 & 0.02 & 0.02 & 0.02 & \\
\hline$A l / S i$ & 0.22 & 0.22 & 0.19 & 0.20 & 0.23 \\
\hline $\mathrm{Mg} / \mathrm{Si}$ & 0.04 & 0.04 & 0.03 & 0.04 & 0.04 \\
\hline
\end{tabular}

表 2 琼簤玻璃陨石热释光特珄*

\begin{tabular}{|c|c|c|c|c|}
\hline \multirow{2}{*}{ 样号 } & \multicolumn{2}{|c|}{ 䉽值温度 $\left({ }^{\circ} \mathrm{C}\right)$} & \multicolumn{2}{|c|}{ 情值 TL 强度 (CPS/mg) } \\
\hline & $N$ & $N+\beta$ & $\boldsymbol{N}$ & $N+\beta$ \\
\hline $02-1$ & 360 & 158360 & 121 & 373215 \\
\hline $02-2$ & 360 & 158360 & 96 & $516 \quad 225$ \\
\hline $06-1$ & 340 & $158 \quad 340$ & 692 & $645 \quad 817$ \\
\hline $06-2$ & 336 & $157 \quad 336$ & 857 & 211894 \\
\hline
\end{tabular}

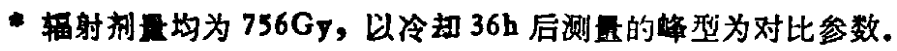

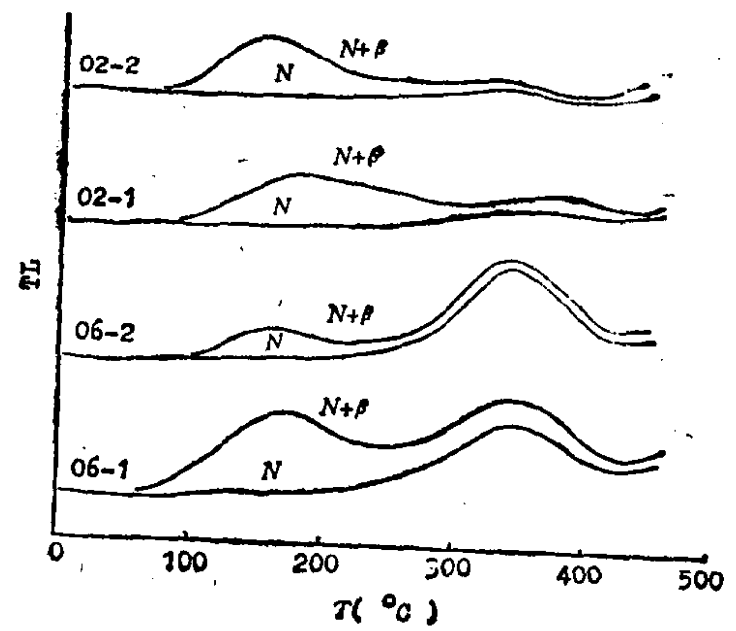

图 1 玻珫陨石热释光曲线

收峰, 蜂态数值如表 3 所列.

吴川(02)与琼山(06)样品相比, 二者因 $\mathrm{OH}$ 伸缩振动产生的吸收峰, 其形态极为相近; 但 
表 3 玻璃陨石红外吸收娢形态

\begin{tabular}{|c|c|c|c|c|c|c|}
\hline \multirow{2}{*}{ 样 枵 } & \multicolumn{3}{|c|}{$1080 \mathrm{~cm}^{-1}$} & \multicolumn{3}{|c|}{$460 \mathrm{~cm}^{-1}$} \\
\hline & 比高 & 蜂 究 & 高/宽 & 蛘高 & 峰 宽 & 高/宽 \\
\hline $02-1$ & 39 & 38 & 1.03 & 30 & 12 & 2.50 \\
\hline $02-2$ & 30 & 35 & 0.86 & 24 & 11 & 2.18 \\
\hline $06-1$ & 34 & 33 & 1.03 & 25 & 10 & 2.50 \\
\hline $06-2$ & 27 & 30 & 0.90 & 21 & 8 & 2.63 \\
\hline
\end{tabular}

曲振动出现的蜂形, 06 样品外层明显窄于02样品,表明两地样品结构不完全一致.

综上所述,我们可以获得如下认识:

1. X射线衍射和红外光谱分析表明,两地样品均系非晶质玻璃体,但在结构上两地样品稍 有差异。

2. 两地样品的化学组成基本一致,其差异主要是 $\mathrm{Al} 、 \mathrm{Fe} 、 \mathrm{Ca} 、 \mathrm{Mg}$ 的含量,吴川样品的这些 元亲含量均明显高于琼山所产样品的含量，但同一地点样品内外层化学组成及其含量是一致 的.

3. 热释光曲线反映的不同样品的特性差异，是因两地样品以及同一地点样品内外层结构 差异引起的,这种差异可能是因受热和冷却历史的不同所造成。因之,他们的陨落年代和地层 意义尚有必要作进一步探讨。

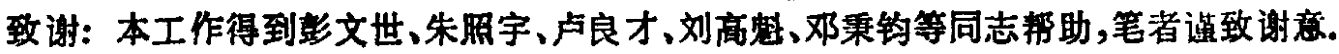

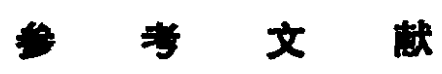

[1]定宝恥、叶连芳,科学通报, 24(1979), 6:271-273.

[2] 产正、曹宝印、叶造芳, 地质科学, 1979, 1:37-41.

[3]欧阳自远、宗和、易倠照,地球化学, 1976, 2:144-146.

[4] 中国科学院原子能研究所、贵阳地球化学研究所协作组,地球化学, 1976, 2:148-155.

[5]许议唧、胡国诨、钟红海、凌育远、陈华堂,地球化学, 1983, 3:322-327.

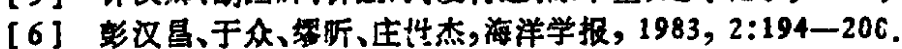

[7] O'Keef, J. A., Tektite and Their Origin. Elsevier, Amersterdam, 1976, 124-127.

[8] Taylor, S. R., Eorth Science Revien, 9(1973), 2: 101-123. 